PP Periodica Polytechnica
Architecture

48(2), pp. 87-92, 2017

https://doi.org/10.3311/PPar.10833

Creative Commons Attribution (1)

RESEARCH ARTICLE

\section{Initial Analysis, Planning and Calculation of Vertical Delivery in High-rise Building Construction}

\author{
Simo Suđić ${ }^{*}$
}

Received 28 February 2017; accepted 01 April 2017

\begin{abstract}
Tower crane plays a vital role in materials delivery in construction projects. General contractors often use technical and commercial quotes to calculate number of cranes and their engagement duration in project, and they often have to deal with commercial and time risks. The main reason for this approach is the lack of standardised methodologies for calculating tower cranes engagement. Identifying the optimal number of cranes, their location and duration of engagement at the building site are the major factors that can reduce the risks considering the time and cost by increasing productivity and thus decreasing the required time. Calculation will be based on different production parameters -space per worker, concrete production per crane or worker, lifting time. This paper presents a methodology for calculating the required number of cranes and their optimal positioning. Proposed model for crane engagement optimisation is developed using the Critical Path Method in Primavera P6 software.
\end{abstract}

\section{Keywords}

construction, optimisation, planning, tower crane

\footnotetext{
${ }^{1}$ Belgrade Waterfront Project, Karađorđeva 48, Belgrade, Serbia

${ }^{*}$ Corresponding author, e-mail: simosudjich@yahoo.com
}

\section{Introduction}

A typical high-rise building construction involves lifting materials of different sizes, types and weights within planned time and under different limitations provided by the logistics as well as the commercial, health \& safety and administrative aspects of the process. For example, concreting works are always in the critical path of high-rise construction projects and tower cranes are therefore crucial for correct planning this phase of the construction process; their engagement has to be planned appropriately. At present, unfortunately, engagement planning for tower cranes is mostly performed intuitively and based on experience (Hasan et al., 2010).

In any construction project, the general construction plan and the logistics plan are among the most important documents. The general construction plan provides the number of cranes and their positioning. Any delays during the pre-construction period (design, approvals and procurement) will affect the construction time, and it will be required to develop a proper mitigation strategy for any of these delays within the construction period. In this case, the best option is to reduce or mitigate delays by increasing the number of cranes and optimising their positions and number, along with the appropriate corrective measures and increasing required resources such as labour, material, other equipment. These measures will increase the production thus reducing the time delay. This paper provides a case study with such analysis for a large commercial construction project with suggestions for possible improvements and optimisation in tower crane's engagement.

\section{Methodology}

The methodology outlined below was employed to determine the necessary number of tower cranes as well as their locations and engagement times for a large commercial construction project. In practice, tower cranes are selected according to the maximum loads to be lifted, the size of the loads, site layout, and their reach or capacity (Hasan et al., 2010).

Proper site organisation and optimum resources engagement can significantly reduce construction cost. The efficiency of concrete works mostly depends on: 
- number, types and position of tower cranes;

- number and specialities of workers on site;

- quantity and type of formwork;

- availability of materials and 'just in time' supply.

Numerous aspects, such as technological sequences, idle time, weather conditions, skill and physical condition of workers, make it difficult to the determine the maximum productivity of a tower crane (Hasan et al., 2010). Table 1 presents data calculated based on production control:

Table 1 Calculation of percentage of crane utilisation (Hasan et al., 2010)

\begin{tabular}{llllll}
\hline $\begin{array}{l}\text { process } \\
\text { name }\end{array}$ & $\begin{array}{l}\text { available } \\
\text { time }(\mathrm{min})\end{array}$ & $\begin{array}{l}\text { cycle time } \\
(\mathrm{min})\end{array}$ & $\begin{array}{l}\text { active } \\
(\mathrm{min})\end{array}$ & $\begin{array}{l}\text { idle } \\
(\mathrm{min})\end{array}$ & $\%$ utilization \\
\hline inspection & 480 & 13 & 429 & 51 & $89.38 \%$ \\
crane 1 & 480 & 15 & 255 & 225 & $53.13 \%$ \\
crane 2 & 480 & 15 & 240 & 240 & $50.00 \%$ \\
installation $\mathrm{L}_{1}$ & 480 & 20 & 340 & 140 & $70.83 \%$ \\
installation $\mathrm{L}_{2}$ & 480 & 20 & 320 & 160 & $66.67 \%$ \\
\hline
\end{tabular}

The presented results are calculated based on percentage utilisation, standard construction method analysis and statistical data from three construction sites in Russia during different weather conditions. It has been found that the maximum percentage of utilisation per crane is only $53.13 \%$. This simple analysis was based on statistical data of concrete poured $\left(\mathrm{m}^{3}\right)$ per month and the number of skilled and unskilled labour assigned to concrete works (reinforcement laying, formworks and concreting).

In general, tower crane utilisation in construction sites is estimated to be $50-80 \%$ (Hasan et al., 2010). Reducing the crane lifting cycle or maximising utilisation of a tower crane can not only increase the productivity but also helps in reducing total project duration.

Savings in crane operations will affect two major operational factors. First, it will shorten the crane cycle time. Second, shortening the crane operation will increase labour productivity.

Savings in crane operation cost can be divided into four categories:

1. Annual ownership cost;

2. Operation cost including fuel, maintenance, license fees, and insurance;

3. Operator cost;

4. Labour cost, i.e. cost of the labourer working directly with the crane.

Since tower cranes stay longer at the site, their rental rates and mobilising costs are high. Therefore, it is not economic to rent a tower crane for projects with longer project duration.
In this paper, tower cranes productivity calculation was conducted according to average production rates from the author's previous experience, as presented in Table 2:

- Optimal number of workers per crane during concrete works $\approx 70$ workers;

- Winter productivity per worker $\approx 16 \mathrm{~m}^{3} /$ month (Russia);

- Summer productivity per worker $\approx 23 \mathrm{~m}^{3} / \mathrm{month}$ (Russia);

Consequently, average production per crane can be defined as:

- Production per crane underground (substructure) $1200 \mathrm{~m}^{3} / \mathrm{crane} / \mathrm{month}$;

- Production per crane above ground (superstructure) $1500-1700 \mathrm{~m}^{3} /$ crane/month.

Table 2 Concrete production and number of workers on site

\begin{tabular}{|c|c|c|c|c|c|c|c|}
\hline & & Jul & Aug & Sept & Oct & Nov & Dec \\
\hline \multirow{2}{*}{ (a) } & (d) & 8.45 & 8.92 & 9.65 & 9.79 & 6.14 & 5.92 \\
\hline & (e) & 375 & 395 & 425 & 465 & 375 & 360 \\
\hline \multirow{2}{*}{ (b) } & (d) & 9.23 & 9.61 & 8.42 & 8.89 & 7.29 & 7.14 \\
\hline & (e) & 390 & 400 & 385 & 395 & 440 & 420 \\
\hline \multirow{2}{*}{ (c) } & (d) & 12.61 & 14.10 & 14.34 & 12.22 & 11.60 & 10.65 \\
\hline & (e) & 555 & 610 & 615 & 580 & 690 & 690 \\
\hline
\end{tabular}

(a) Construction site 1 (commercial $185,000 \mathrm{~m}^{3}$ of concrete)

(b) Construction site 2 (commercial $210,000 \mathrm{~m}^{3}$ of concrete)

(c) Construction site 3 (commercial $320,000 \mathrm{~m}^{3}$ of concrete)

(d) Concrete q-ty (m3)

(e) Number of workers

It is of essential importance to plan concrete pouring very carefully, and it must be a part of the project logistics plan, general construction plan and technology statement. It can be developed based on concrete quantities from the schematic design, which will form the basis for the initial time programme. Concrete foundations and frames are always on the critical path and subjected to numerous constraints such as logistics, availability of concrete plants, traffic, pumps, tower cranes. Tower cranes are primarily used for moving reinforcement, formwork, brickwork and concrete columns and for concrete pouring.

In this paper, two optimisation steps are analysed: the determination of the minimal required number of tower cranes and optimising locations of tower cranes to minimise potential overlapping between tower cranes and surrounding facilities. Each crane has a load chart that specifies lifting capacity. The maximum capacity is always obtained by the shortest crane's operating radius (Irizarry and Karan, 2012).

For the proper planning of crane utilisation, it is very important to define various phases of construction. Usually, underground and above ground construction works are significantly different from the point of view of tower cranes engagement. It is recommended to reduce or mitigate delays by increasing or optimising the number and position of cranes, along with the 
adequate corrective measures and increasing required resources (labour, material, other equipment), which would increase the production thus reduce the delay.

A suitable general construction plan should define the optimal position of the tower cranes. According to (Tork, 2014), in order to lift a load with the weight $w$ to a supply point $S$, the tower crane should be placed within a circle centred at $S$ and with lifting radius $R$, where $R$ is the minimum of the tower crane's jib length $\left(C_{r}\right)$ with operating radius $(r)$ obtained from a load chart. In the proposed model, it is possible to consider more than one demand point for each supply point. In reality, there may be more than one feasible area within a construction site. A tower crane can handle two tasks if it is located within the intersection of operating areas (Fig. 1).

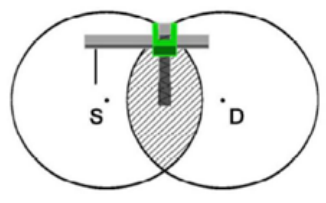

(a)

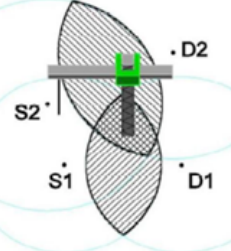

(b)
Fig. 1 Feasible task area for supply (S) and demand (D) points: (a) single task; (b) multiple tasks (Irizarry and Karan, 2012).

If there is no overlap between task areas, then a single tower is not enough to handle both. The geometric closeness of tasks can be measured by the size of the overlapping area (the larger the overlapping area, the greater closeness). A larger overlapping area between two or more cranes may result in a longer presence of the cranes in the shared area and therefore an increased risk of collision (Emsley, 2010). Consequently, this model searches for places with the minimum overlapping area between cranes and their surrounding facilities.

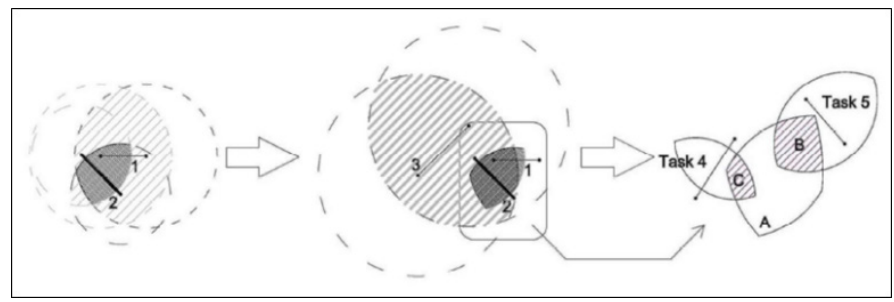

Fig. 2 Task closeness (Irizarry and Karan, 2012)

\section{Case study}

In presented case study, tower crane management on a commercial project in Moscow, Russian Federation, is analysed. The project consisted of 420,000 $\mathrm{m}^{2}$ GFA (hotel, office and residential buildings with 2 to 3 floors of underground parking). An international bank financed the project, and the main contract was appointed under cost plus (open-book) guaranteed maximum price. The time schedule was previously agreed and was exposed to many risks due to challenges in logistics, weather conditions, subcontractors' performance and coordination. The employer (investor) wanted to optimise the crane usage for maximum benefit as well as to have it dismantled within two months after the completion of concrete works.

Tower cranes are intensively used during structural concrete works for vertical transportation of reinforcement and formwork as well as for concreting walls and columns. Works underground and above ground are significantly different because below the zero-level several activities can be performed in parallel with concrete works (waterproofing, excavation, dewatering, protection of foundation pit), and works schedule depends on coordination and technological links between activities. Tower cranes for construction above the zero-level are mostly used for concrete works as well as for transportation of other materials for brickwork partitions and the façade in parallel, depending on the availability. For the optimal use of tower cranes, project phases need to be appropriately defined, and the necessary number of cranes should be carefully planned for each phase.

The maximum quantity of concrete planned to be poured monthly on the construction site was $8,000 \mathrm{~m}^{3}$ for the underground works. Simple calculations based on production rates proposed in the above figure provides the optimum result - five cranes with 350 skilled workers to achieve the planned monthly concrete works of $8,000 \mathrm{~m}^{3}$. At the actual building site, two additional cranes were installed to achieve the planned concrete production.

For the approximate estimation of crane engagement duration, planning tools like Microsoft Project, Primavera, Asta Power Project are used.

(www.https://www.microsoft.com/.../evaluate-project-professional20..;https://www.oracle.com/applications/primavera/; www.astapowerproject.com/software/asta-powerproject/)

According to the contract milestone table and durations, the time schedule was prepared using software Primavera Enterprise P8.2 (https://www.oracle.com/applications/primavera/) with works breakdown structure (WBS) defined as underground and above ground. Concrete quantities were defined as resources, with linear distribution as shown in Fig. 4; the histogram of concrete to be poured monthly is obtained. This plan is very similar to one presented in Table 3 . The crane allocation is shown in the programme as 'level of effort' activities as separate WBS.

In the presented case, concrete distribution was assumed to be linear, but there is also the possibility to set some other type of distribution, such as front or back loaded, bell-shaped or normal. In Table 3, the concrete plan with crane calculation and number of workers required has already been presented.

Maximum concrete poured per month $=$ number of cranes $\mathrm{x}$ number of workers per crane [average number of workers per crane $=70] \times$ production/worker/month (calculation on the upper part of Fig. 3). 
Table 3 Concrete production and number of workers on site

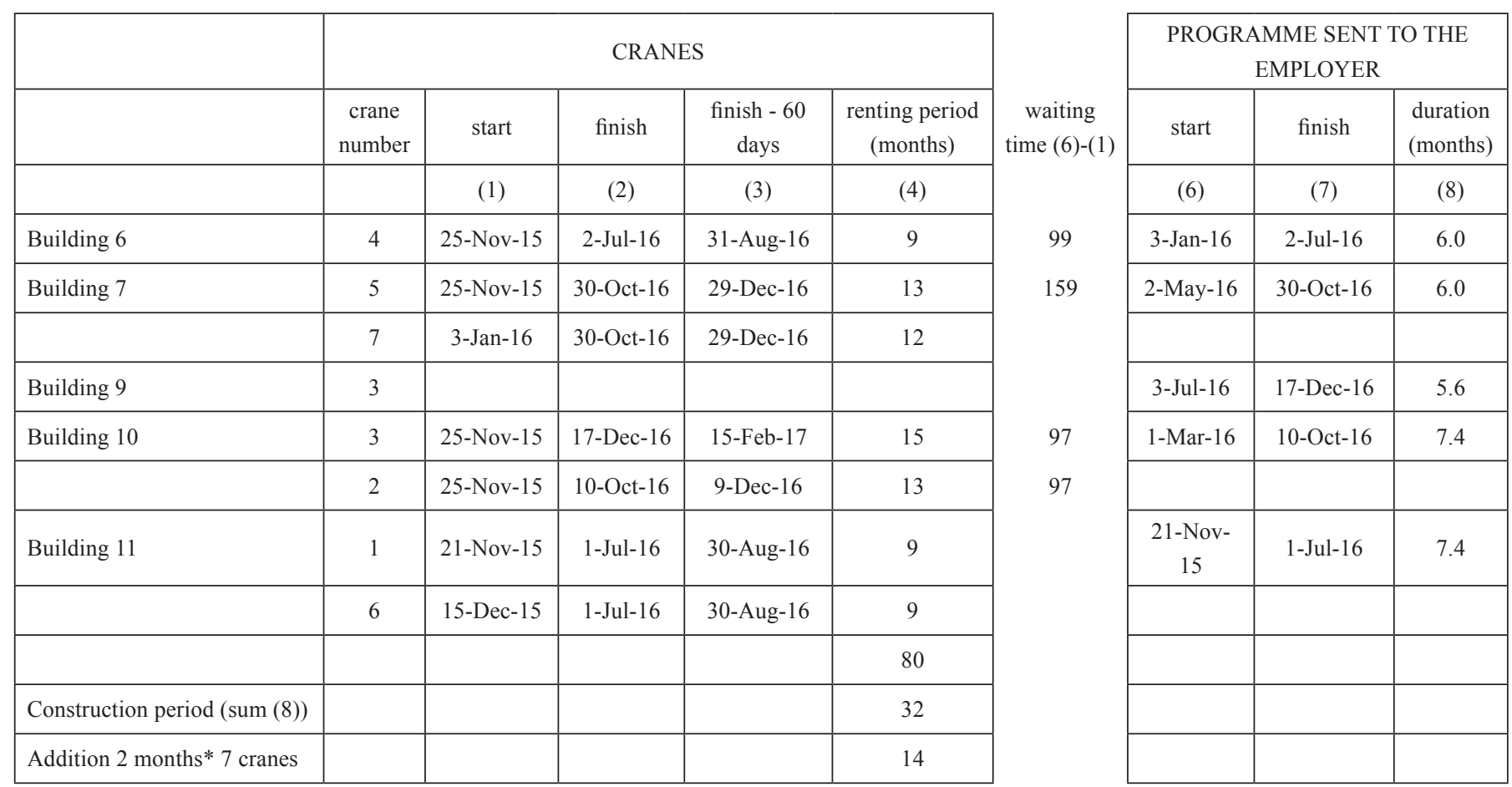

\begin{tabular}{|l|c|c|c|c|c|}
\hline Zone of "top\&down" & & & & & \\
\hline Building 8 & A & 1-Aug-15 & 3-Sep-16 & 2-Nov-16 & 15 \\
\hline Building 12 & B & 15-Jul-15 & 4-Sep-16 & 3-Nov-16 & 16 \\
\hline & C & 15-Aug-15 & 4-Sep-16 & 3-Nov-16 & 15 \\
\hline & & & & & 46 \\
\hline
\end{tabular}

\begin{tabular}{|l|l|l|}
\hline & & \\
\hline 4-Oct-15 & 3-Sep-16 & 11.2 \\
\hline 7-Sep-15 & 4-Sep-16 & 12.1 \\
\hline & & \\
\hline & & \\
\hline
\end{tabular}

Number of cranes $=$ square meter of slabs poured per month / average production per crane (calculation on the lower part of Fig. 3).

Table 3 and Fig. 3 show the same procedure, but for better understanding and presentation it is firstly conducted using the planning and scheduling software in Fig. 3 and afterwards exported to Microsoft Excel, as given in Table 3, for the calculating the concreting schedule, labour and number of cranes required.

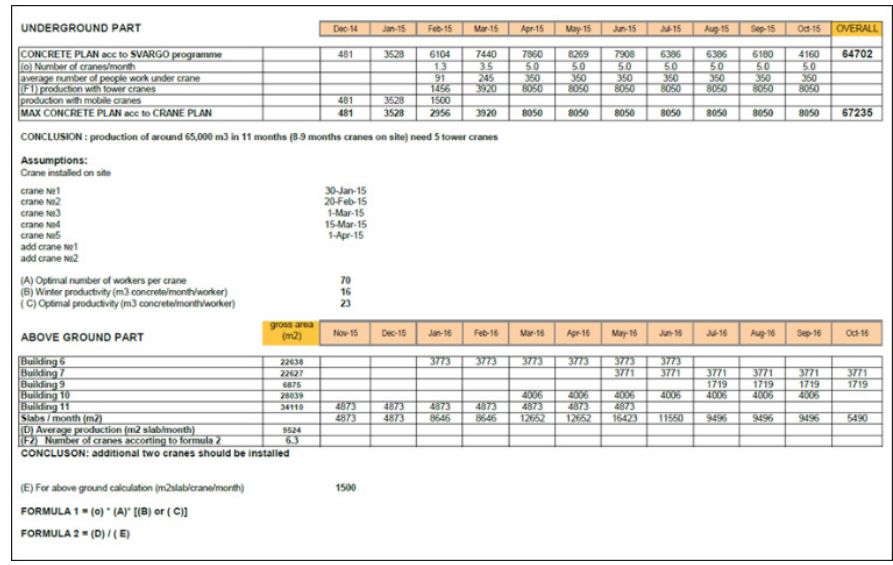

Fig. 3 Number of crane calculation based on concrete plan and proposed production rates

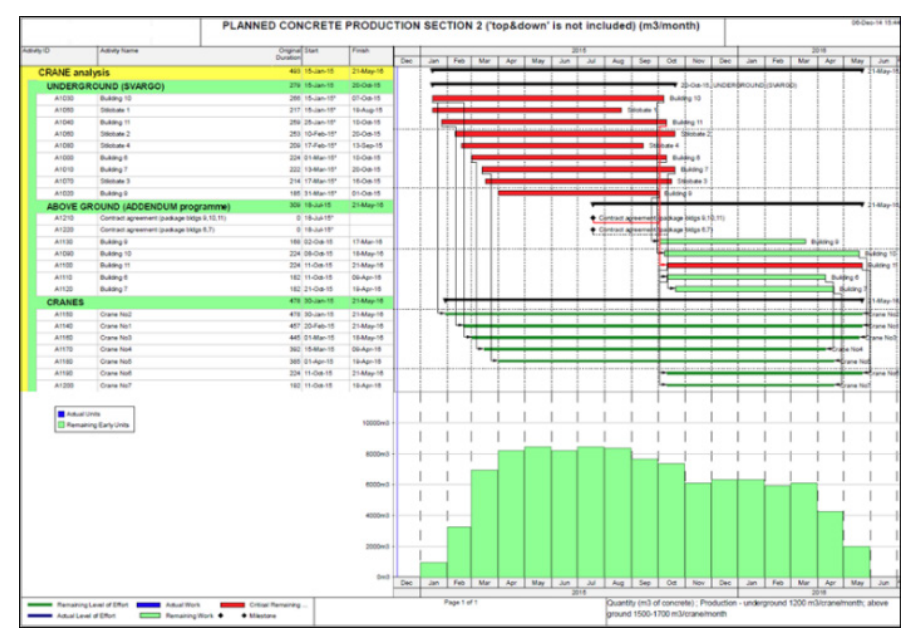

Fig. 4 Planned concrete production and crane loading during concrete works.

In Fig. 5, similarly to that presented in Fig. 3, the black fields present the planned period for construction, and the pink fields present the planned period of crane installation on site.

The renting company proposed the number of cranes and layout presented in Fig. 6. Using methodology of supply and demand points, as well as an analysis of conflicted areas and bearing in mind calculated production rates, it was concluded 
that the proposed number of cranes was unnecessarily high and that there are many conflicted areas between cranes. A large overlapping area between two or more cranes may result in a longer presence of the cranes in the shared area and therefore a high risk of collision. Even though this number of cranes would provide high productivity, their individual utilisation would be relatively low. Besides this, the installation and dismantling cost for such number of cranes would be very high. Because of this, the crane company's proposal was rejected.

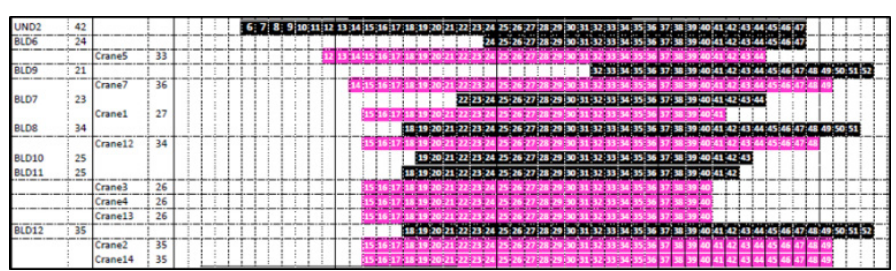

Fig. 5 Time schedule and crane engagement per building

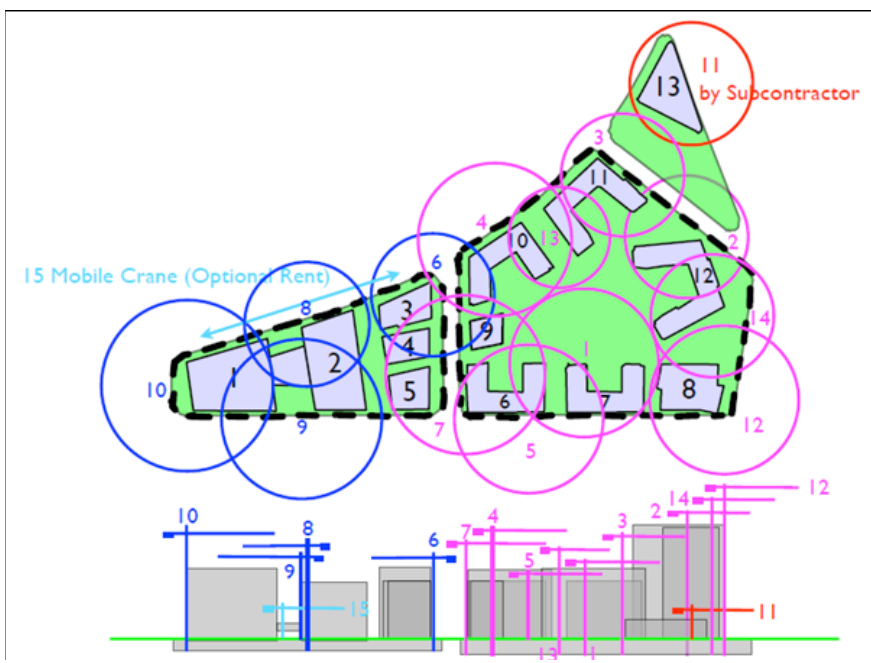

Fig. 6 Crane layout proposed by the renting company

For Phase 2 (construction of buildings 6 to 12), which is the point of concern in this paper, the crane company proposed nine cranes; however, according to the calculations in Fig. 3, a sufficient number of cranes to achieve the schedule would be 6.3 (7). The general contractor analysed the proposed crane layout, position of buildings (demand points) and supply points, and suggested a better strategy to achieve the project schedule.

Table 3 presents the calculation of overall crane usage at the construction site based on concrete works schedule; this enables a decision maker to determine the cost of cranes and to analyse possible solutions for crane engagement. This calculation is based on a very aggressive approach to fulfilling the demand that cranes have to be dismantled two months after completion of the concrete works.

After analysing the proposal from the crane renting company (Fig. 6), the calculation presented in Table 3 and the construction schedule, it was decided to organise vertical transportation with tower cranes as presented in Fig. 7. Although calculations showed that only seven cranes would be required, after expert analysis with all possible assumptions, it was decided to install eight cranes for the construction of Phase 2. The main reason for including one additional crane was the restricted position of supply points, as well as including a margin of error in case of any unpredicted risk and to reduce construction time. With this strategy, the utilisation of tower cranes was higher than the average referenced in the literature. (Irrizary and Karan, 2012; Hasan et al., 2010).

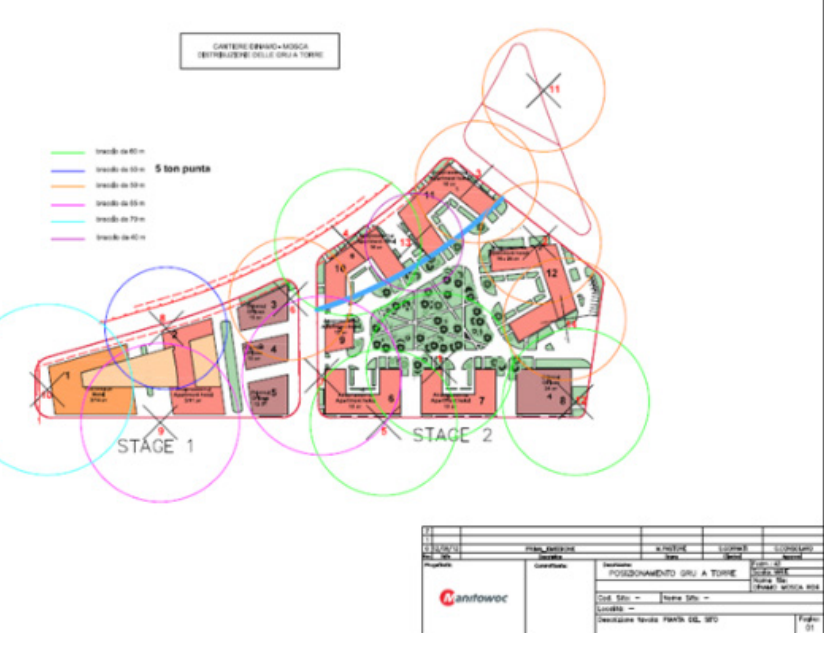

Fig. 7 Tower cranes layout proposed by the crane renting company and General Contractor

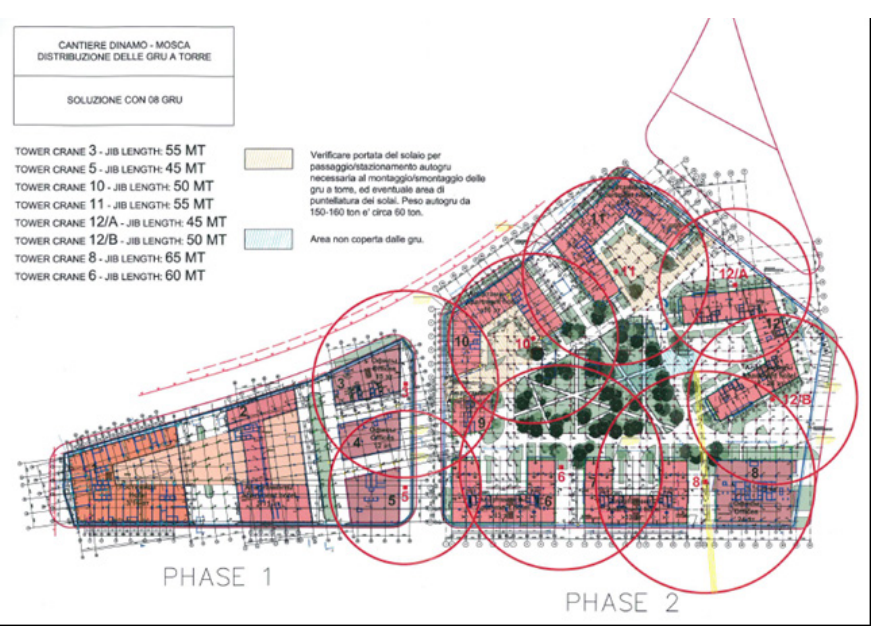

Fig. 8 Construction plan with the position of tower cranes for Phase 2.

\section{Conclusion}

This overview and analysis is an attempt to present and clarify the main topics related to crane engagement analysis, calculation and management in high-rise building construction. A case study based on previous project experience should be analysed and confirmed at the end of the project with statistical data collected during the execution period. The proposed approach for determining the required number of cranes and their positions can be further improved with different productivity rates; this would depend on the details of a given construction site, building type, climate, technological and organisational factors. Proper positioning of a crane should be defined 
considering supply and demand points, which is mostly a geometrical approach. This problem should always be analysed from the planning perspective as productivity and duration of crane engagement at the construction site have a considerable impact on many aspects of the construction process.

\section{References}

Emsley, M.W. (2001). A model to optimise single tower crane location within a construction site. A Doctoral Thesis, Loughborough University.

Irizarry, J., Karan, E. P. (2012). Optimizing location of tower cranes on construction sites through GIS and BIM integration. Journal of Information Technology in Construction. 17, pp. 351-366.

Hasan, S., Al-Hussein, M., Gillis, P. (2010). Advanced simulation of tower crane operation utilising system dynamics modelling and lean principles. In: Proceeding of the 2010 Winter Simulation Conference, pp. 3262-3271.

Tork, A. (2013). A real time crane service scheduling decision support system (CSS-DSS) for construction tower cranes. A Doctoral Dissertation, University of Central Florida, Orlando, Florida. 